Marquette University

e-Publications@Marquette

$10-1-2015$

\title{
Sex Differences with Aging in the Fatigability of Dynamic Contractions
}

Tejin Yoon

Marquette University, tejin.yoon@marquette.edu

Ryan E. Doyel

Creighton University

Claire Widule

Marquette University

Sandra K. Hunter

Marquette University, sandra.hunter@marquette.edu

Accepted version. Experimental Gerontology, Vol. 70 (October 2015): 1-10. DOI. (C) 2015 Elsevier Inc. Used with permission. 


\title{
Sex Differences with Aging in The Fatigability of Dynamic Contractions
}

\author{
Tejin Yoon \\ Exercise Science Program, Department of Physical Therapy, \\ Marquette University, Milwaukee, WI \\ Department of Kinesiology and Integrative Physiology, \\ Michigan Technological University, Houghton, MI \\ Ryan Doyel \\ Exercise Science Program, Department of Physical Therapy, \\ Marquette University, Milwaukee, WI \\ Creighton University School of Medicine, Omaha, NE \\ Claire Widule \\ Exercise Science Program, Department of Physical Therapy, \\ Marquette University, Milwaukee, WI \\ Uniformed Services University of the Health Sciences, F. Edward \\ Hebert School of Medicine, Bethesda, MD

\section{Sandra K. Hunter} \\ Exercise Science Program, Department of Physical Therapy, \\ Marquette University, Milwaukee, WI
}


Abstract: This study determined the sex difference with aging in fatigability of the elbow flexor muscles during a dynamic fatiguing task, and explored the associated mechanisms. We compared fatigability of the elbow flexor muscles in 18 young (20.2 \pm 1 years: 9 men) and 36 old adults ( $73.5 \pm 1$ years: 16 men) during and in recovery from repeated dynamic contractions ( $~ 60 \%$ s) with a load equivalent to $20 \%$ of maximal voluntary isometric contraction (MVIC) torque until failure. Transcranial magnetic stimulation (TMS) was used to assess supraspinal fatigue (an increase in the superimposed twitch, SIT) and the peak rate of muscle relaxation. Time to failure was briefer for the men than the women $(6.1 \pm 2.1$ vs. $9.7 \pm 5.5 \mathrm{~min}$, respectively; $\mathrm{P}=0.02)$ with no difference between young and old adults ( $7.2 \pm 2.9$ vs. $8.4 \pm 5.2 \mathrm{~min}$, respectively, $P=0.45)$ and no interaction $(P>0.05)$. The relative decline in peak relaxation rate with fatigability was similar for young and old adults $(P=0.11)$, but greater for men than women $(P=0.046)$. Supraspinal fatigue increased for all groups and was associated with the time to failure $(P<0.05)$. Regression analysis however, indicated that the time to failure was best predicted by the peak relaxation rate (baseline values and slowing with fatigability) $\left(r^{2}=0.55\right)$. Rate-limiting contractile mechanisms (e.g. excitation-contraction coupling) were responsible for the increased fatigability of the elbow flexors of men compared with women for a dynamic fatiguing task of slow angular velocity, and this sex difference was maintained with aging. The age difference in fatigability for the dynamic task was diminished for both sexes relative to what is typically observed with isometric fatiguing contractions.

\section{Abbreviations}

- ANOVA, Analysis of Variance;

- EMG, electromyography;

- MEP, motor evoked potential;

- Mmax, Maximal M wave;

- $\quad$ MVCC, maximal voluntary concentric contraction;

- MVIC, maximal voluntary isometric contraction;

- M wave, compound muscle action potential;

- RPE, rating of perceived exertion;

- TMS, transcranial magnetic stimulation;

- $\quad$ SIT, superimposed twitch

Keywords: Muscle fatigue, Contractile properties, Supraspinal fatigue, Aging, Gender, Women

\section{Introduction}

Fatigability is the reduction in expected force or power during a fatiguing task and it develops soon after the onset of sustained and repeated intermittent contractions (Kluger et al., 2013, Kent-Braun et al., 2012 and Enoka, 2012). Fatigability is classically quantified as a reduction in maximal force or power and also as the time to failure of a

Experimental Gerontology, Vol 70 (October 2015): pg. 1-10. DOI. This article is @ Elsevier and permission has been granted for this version to appear in e-Publications@Marquette. Elsevier does not grant permission for this article to be further copied/distributed or hosted elsewhere without the express permission from Elsevier. 
submaximal task (Gandevia, 2001 and Enoka, 2012). Age-related differences within the neuromuscular system of men and women will impact physiological adjustments during a fatiguing task so that old adults exhibit different rates of fatigability than young adults. Old adults, for example, are less fatigable than young adults during isometric contractions of lower and upper limb muscles (Avin and Frey Law, 2011 and Christie et al., 2011). However, age-related differences in fatigability during dynamic contractions are typically minimized at slow speeds of shortening (Lindstrom et al., 1997, Yoon et al., 2013 and Callahan et al., 2009) or reversed so that old adults are more fatigable than young adults for high angular velocity contractions (Dalton et al., 2010b, McNeil and Rice, 2007, Petrella et al., 2005, Dalton et al., 2012 and Callahan and Kent-Braun, 2011). These studies have assessed age-related fatigability mostly of the lower limb (Dalton et al., 2010b, Dalton et al., 2012, Callahan et al., 2009, Callahan and Kent-Braun, 2011, McNeil and Rice, 2007 and Baudry et al., 2007) with minimal data for the upper limb. Recently, we showed that among men, the greater fatigue resistance of the elbow flexor muscles in old adults compared with young adults for a sustained isometric contraction was diminished during a dynamic fatiguing contraction task at a relatively slow angular velocity (Yoon et al., 2013). Whether this occurs in the elbow flexor muscles for women who typically have a more fatigue resistant muscle than men during isometric contractions (Hunter, 2014) is not known. Furthermore, the mechanism for this age-related dependence in fatigability on angular velocity is not fully understood.

Loss of voluntary activation will contribute to a loss of torque after dynamic contractions in both young and old adults, but does not appear to be the primary mechanism for the task dependent age difference in fatigability (Yoon et al., 2013). Dynamic contractions involve greater metabolic demand than a sustained isometric contraction (Newham et al., 1995) and therefore the greater metabolic demand may have larger effects on the slower muscle of the old adults during fast dynamic contractions (Callahan and Kent-Braun, 2011 and Dalton et al., 2012). This study will establish those mechanisms that limit a slow velocity fatiguing task performed with the elbow flexor muscles in both men and women.

Experimental Gerontology, Vol 70 (October 2015): pg. 1-10. DOI. This article is (C) Elsevier and permission has been granted for this version to appear in e-Publications@Marquette. Elsevier does not grant permission for this article to be further copied/distributed or hosted elsewhere without the express permission from Elsevier. 
Although young women are typically less fatigable than young men during isometric fatiguing contractions (Hunter, 2014), much less is known about the sex differences during and in recovery from a dynamic fatiguing task. The findings to date indicate that women are either less fatigable than men for a dynamic task (Pincivero et al., 2003) or the sex difference is diminished (Clark et al., 2003, Pincivero et al., 2004, Senefeld et al., 2013 and Miller et al., 1993). The sex difference in fatigability seen in young adults during an isometric contraction can be diminished with age (Hunter, 2009 and Hunter et al., 2004a), but there are no studies determining whether this occurs during a dynamic fatiguing task. Furthermore, old men and women recover more slowly than young after an isometric fatiguing contraction partly due to decrements in neural drive (Hunter et al., 2008, Yoon et al., 2012 and Dalton et al., 2010a). Reductions in neural drive during recovery from isometric fatiguing contractions were demonstrated with an increase in fatigability originating from supraspinal sources assessed with transcranial magnetic stimulation (TMS), and as lower motor unit discharge rates during the recovery of maximal voluntary isometric contractions (Hunter et al., 2008, Yoon et al., 2012 and Dalton et al., 2010a). Recovery of torque and power from a dynamic fatiguing contraction task and the contributing mechanisms have not been compared among old men and women.

The purpose of this study was to compare fatigability and the fatigue-related mechanisms in young and old men and women for a dynamic task with the elbow flexor muscles. We hypothesized that 1) young and old women would have a similar time to failure for the dynamic fatiguing task of the upper limb slowly-paced angular velocity contractions, as we had observed for men (Yoon et al., 2013); 2) the sex difference in time to failure for the dynamic fatiguing task would be diminished among old adults; 3) contractile mechanisms would explain the variance among individuals between the groups; and 4) supraspinal fatigue (shown as the increase in the superimposed twitch during a maximal contraction) would increase after the fatiguing contraction similarly for men and women but would be greater in older than the young adults during recovery.

Experimental Gerontology, Vol 70 (October 2015): pg. 1-10. DOI. This article is (C) Elsevier and permission has been granted for this version to appear in e-Publications@Marquette. Elsevier does not grant permission for this article to be further copied/distributed or hosted elsewhere without the express permission from Elsevier. 
NOT THE PUBLISHED VERSION; this is the author's final, peer-reviewed manuscript. The published version may be accessed by following the link in the citation at the bottom of the page.

\section{Methods}

Eighteen young adults ( 9 men and 9 women, 18-26 years) and 36 old adults (16 men and 20 women, 66-84 years) volunteered to participate in experiments that involved a dynamic fatiguing task with the left elbow flexor muscles. Some of the data of the men were published in an earlier paper (Yoon et al., 2013). All participants were healthy with controlled blood pressure and no known neurological diseases; and all were naive to the protocol. Prior to the experimental sessions, each participant provided written informed consent, and the protocol was approved by the Marquette University Institutional Review Board.

All participants attended a familiarization session that involved a physical activity questionnaire (Kriska and Bennett, 1992); habituation of the electrical-stimulation to the brachial plexus and transcranial magnetic stimulation (TMS) to the motor cortex; and practice of brief submaximal contractions, maximal voluntary isometric contractions (MVIC) and maximal voluntary concentric contractions (MVCC). Hand dominance was estimated using the Edinburgh Handedness Inventory (Oldfield, 1971) with a ratio of 1 indicating complete right-handedness. The experimental session involved performance of a dynamic fatigue task with a load equivalent to $20 \%$ of MVIC torque. The dynamic fatiguing task involved shortening activation to lift the load through a 90-degree range of movement followed by lengthening activation to lower the load to the start, and this was repeated every $3 \mathrm{~s}$ for as long as possible.

\subsection{Participant set-up and mechanical recordings}

Each participant was seated upright in an adjustable chair with the left arm slightly abducted. The elbow was resting comfortably on a padded support, and the elbow joint was flexed to $90^{\circ}$ so that the forearm was horizontal to the ground when measuring MVIC. The participant's shoulders were restrained by two nylon straps to minimize shoulder movement. The hand and forearm were placed in a modified rigid wrist-hand-thumb orthosis (Orthomerica, Newport Beach, CA) midway between pronation and supination and the force was directed upward when the elbow flexor muscles were activated.

Experimental Gerontology, Vol 70 (October 2015): pg. 1-10. DOI. This article is (C) Elsevier and permission has been granted for this version to appear in e-Publications@Marquette. Elsevier does not grant permission for this article to be further copied/distributed or hosted elsewhere without the express permission from Elsevier. 
The forces exerted at the wrist in the vertical directions during the MVIC, were measured with a force transducer (Force-Moment Sensor, JR-3, Woodland, CA) that was mounted on a custom designed, adjustable support. The orthosis was fixed to the force transducer. For the dynamic contraction a potentiometer (Alpha Product Inc., $16 \mathrm{~mm}$ Rotary type, Oxnard, CA) was mounted to the axis of rotation of the elbow support. The angles detected by the potentiometer and the forces detected by the force transducer were recorded online using a Power 1401 A-D converter and Spike 2 software [Cambridge Electronics Design (CED), Cambridge, UK]. The force and angle signals were digitized at 500 samples/s and displayed on a 19-in monitor located $1.5 \mathrm{~m}$ in front of the participant.

\subsection{Electrical recordings}

Electromyography (EMG) signals were recorded with a bipolar configuration using surface electrodes $(\mathrm{Ag}-\mathrm{AgCl}, 8-\mathrm{mm}$ diameter; $16 \mathrm{~mm}$ between electrodes) that were placed over the biceps brachii, brachioradialis, and triceps brachii muscles according to recommended placements (Hermens et al., 2000). For biceps brachii, the electrodes were place between the medial acromion and the fossa cubit at $1 / 3$ the distance from the cubital fossa (Hermens et al., 2000). For the brachioradialis, the electrodes were placed on the muscle belly $\sim 4 \mathrm{~cm}$ distally from the lateral epicondyle. For the triceps brachii, the electrodes were placed on the long head at 50\% the distance between the posterior crista of the acromion and the olecranon at 2 finger widths medial to the line.

Reference electrodes were placed on the lateral epicondyle of the elbow. The EMG signals were amplified $(100 \times)$ and band-pass filtered (13-1000 Hz) with Coulbourn modules (Coulbourn Instruments, Allentown, PA). The EMG signals were recorded online via a Power 1401 A-D converter (CED). The EMG signals were digitized at 2000 samples/s.

\subsection{Stimulation}

Participants were stimulated at the brachial plexus with electrical stimulation and at the motor cortex with TMS.

Experimental Gerontology, Vol 70 (October 2015): pg. 1-10. DOI. This article is @ Elsevier and permission has been granted for this version to appear in e-Publications@Marquette. Elsevier does not grant permission for this article to be further copied/distributed or hosted elsewhere without the express permission from Elsevier. 
NOT THE PUBLISHED VERSION; this is the author's final, peer-reviewed manuscript. The published version may be accessed by following the link in the citation at the bottom of the page.

\subsubsection{Brachial plexus stimulation}

The brachial plexus was electrically stimulated to produce a maximal compound muscle action potential (maximal $M$ wave: $M_{\max }$ ) of the biceps brachii, brachioradialis and triceps brachii muscles. A constant-current stimulator (model DS7AH, Digitimer, Welwyn Garden City, Hertfordshire, UK) was used to deliver single stimuli (400 V and $100 \mu s$ duration) to the brachial plexus. A cathode was placed in the supraclavicular fossa and an anode on the acromion. The stimulation intensity was determined by increasing the current until the peak-topeak $M$ wave amplitude plateaued, then the stimulation intensity was increased by $20 \%$ to ensure a maximal electrical response. The stimulation intensity ranged between 120 and $300 \mathrm{~mA}$ and once this intensity was determined, this level of stimulation was used for the remainder of the protocol.

\subsubsection{Motor cortex stimulation}

TMS stimulation was delivered via a round coil $(13.5-\mathrm{cm}$ outside diameter) over the vertex (Magstim 200, Magstim, Whitland, UK) to evoke motor-evoked potentials (MEPs) from the biceps brachii, brachioradialis and triceps brachii muscles. The vertex of the motor cortex was identified and the scalp marked to ensure repeatability of coil placement throughout the protocol. The right cerebral hemisphere was stimulated by the direction of the current flow in the coil to preferentially activate the left limb. A single pulse was delivered over the motor cortex. The intensity of the stimulation was increased by $5 \%$ of stimulator maximal output until optimal MEP responses of elbow flexors and extensor were found. The stimulation intensity was determined as the intensity that produced a large MEP in the agonist biceps brachii muscle (minimum amplitude of $50 \%$ of $M_{\max }$ during a brief contraction of the elbow flexor muscles at $50 \%$ of MVIC intensity) and a small MEP of the triceps brachii (Todd et al., 2004).

\subsection{Experimental protocol}

Optimal levels of stimulation intensities to the motor cortex and brachial plexus were determined, and these levels remained constant throughout the rest of the protocol. The protocol then involved MVICs

Experimental Gerontology, Vol 70 (October 2015): pg. 1-10. DOI. This article is (C) Elsevier and permission has been granted for this version to appear in e-Publications@Marquette. Elsevier does not grant permission for this article to be further copied/distributed or hosted elsewhere without the express permission from Elsevier. 
of the elbow flexor and extensor muscles, followed by maximal shortening contractions (MVCC), a dynamic fatiguing task and 10 min of recovery measures with the elbow flexor muscles (Fig. 1).

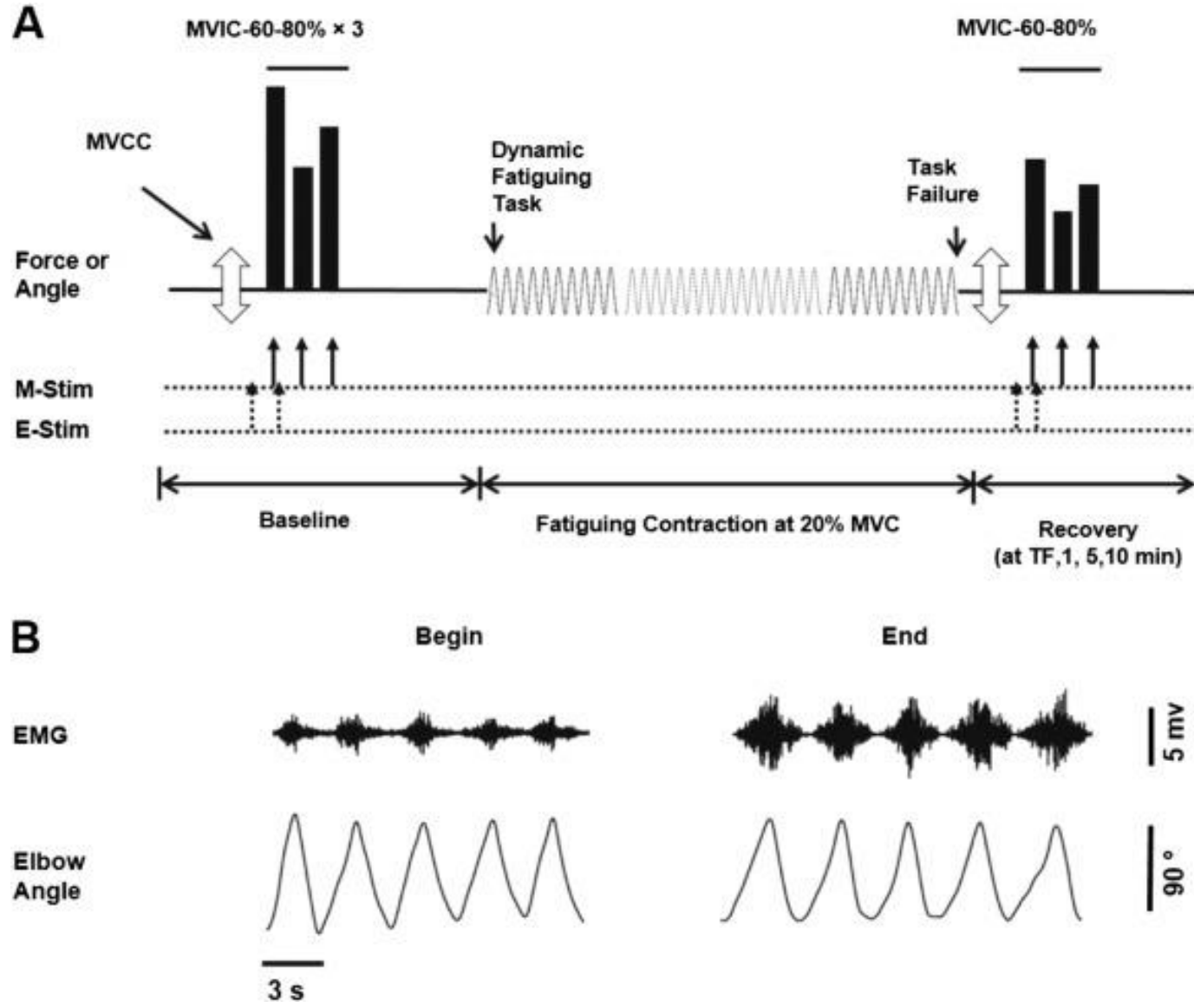

Fig. 1. Experimental protocol and representative data. (A) The order of torque and power tasks performed by each participant with the elbow flexor muscles. Three maximal voluntary concentric contractions (MVCC, open arrow) were followed by sets of 3 brief contractions shown in solid bars [maximal voluntary isometric contractions (MVIC), 60\% and $80 \%$ MVIC] before (baseline) and in recovery from the fatiguing contraction. Recovery measures occurred at task failure and at 1, 5 and 10 min postfatigue (recovery). The dynamic fatiguing task with a load of $20 \%$ MVIC is symbolized with the sine wave, and was performed until task failure (TF). Fig. $1 \mathrm{~A}$ is not to scale. (B) Representative data for an old male subject. Shown are the interference EMG and elbow angle for 5 contractions at the start and toward the end of dynamic fatiguing task.

\subsubsection{Maximal Voluntary Isometric Contractions (MVIC)}

Two MVICs of the elbow extensor muscles separated by 1 min of rest were performed so that peak EMG values could be obtained to normalize the triceps EMG activity during the fatiguing contraction. 
Four sets of brief isometric contractions (2-3 s each contraction) with the elbow flexor muscles were performed and separated by 2 min of rest to minimize fatigue. Each set involved performance of a MVIC followed by contractions at $60 \%$ and $80 \%$ MVIC. The brief contractions at $60 \%$ and $80 \%$ MVIC were performed to estimate the resting twitch amplitude (see the Data Analysis section for more details). Within each set, the start of each contraction was separated by $\sim 4 \mathrm{~s}$. If peak torques from two of the four MVIC trials were not within $5 \%$ of each other, additional trials were performed until this was accomplished. TMS was delivered during each contraction, and brachial plexus stimulation was delivered during the MVICs. Sets of contractions (MVIC, 60\% and 80\% MVIC) with the above described stimulation were also performed several times during 10 min of recovery (see below for recovery times).

\subsubsection{Maximal Voluntary Concentric Contraction (MVCC)}

Each participant performed two consecutive concentric (shortening) contractions with the elbow flexor muscles between an elbow joint angle of $135^{\circ}$ to $45^{\circ}$ as fast as possible. Each participant lifted a weight equal to $20 \%$ of MVIC torque. During the remainder of the protocol, the two MVCCs were performed before each MVIC. The fastest one of two contractions was reported as the MVCC.

\subsubsection{Fatiguing contraction}

A dynamic fatiguing contraction task was performed with the elbow flexor muscles with a weight equal to $20 \%$ of MVIC torque until task failure. Each participant moved the weight through a $90^{\circ}$ range of motion $\left(45^{\circ}\right.$ to $135^{\circ}$ ) at 1 cycle every $3 \mathrm{~s}$ so that the average angular velocity was $60^{\circ} / \mathrm{s}$. Each cycle involved first lifting the inertial load (concentric or shortening phase) through the $90^{\circ}$ range of motion followed by lowering the load (eccentric or lengthening phase) to the start position within the 3 second time limit. A metronome was used to indicate the start of each 3-second cycle. Visual feedback of joint angle was displayed on a 19-in. monitor with the upper and lower limits of range of motion shown. The monitor was located $1.5 \mathrm{~m}$ in front of the participant. Each participant was verbally encouraged and the fatiguing contraction was terminated when an automated computer program (Spike 2, CED) indicated that a range of motion between 45 and $135^{\circ}$

Experimental Gerontology, Vol 70 (October 2015): pg. 1-10. DOI. This article is @ Elsevier and permission has been granted for this version to appear in e-Publications@Marquette. Elsevier does not grant permission for this article to be further copied/distributed or hosted elsewhere without the express permission from Elsevier. 
NOT THE PUBLISHED VERSION; this is the author's final, peer-reviewed manuscript. The published version may be accessed by following the link in the citation at the bottom of the page.

could not be achieved in each 3-s cycle for 2 of 3 consecutive contractions. The duration of the task was recorded as the time to task failure.

\subsubsection{Recovery measures}

Sets of MVCCs followed by a MVIC and submaximal contractions (60\% and $80 \%$ MVIC) were performed during recovery at the following times: immediately upon task failure, $1 \mathrm{~min}, 5 \mathrm{~min}$ and $10 \mathrm{~min}$ after termination of the fatiguing contraction.

\subsection{Data analysis}

The MVIC force was quantified as the average value over a $0.5-\mathrm{s}$ interval that was centered about the peak of the MVIC. The torque for the MVIC and submaximal contractions was calculated as the product of force and the distance between the elbow joint and the point at which the wrist was attached to the force transducer. The average contraction velocity for MVCC was quantified as the average angular velocity for concentric (shortening) phase (45 to $\left.135^{\circ}\right)$. The MVCC with the maximal angular velocity of the two consecutive MVCCs performed on each occasion was taken for analysis. The peak power (watts) was calculated as the product of angular velocity and the torque for the 20\% MVIC.

The maximal EMG activity for each muscle was determined as the Root Mean Square (RMS) value during the MVIC over the same 0.5 -s interval that the MVIC torque was determined. The RMS of the EMG signal of the elbow flexor muscles and triceps brachii muscles were quantified during the first and last five contractions of the dynamic task. The RMS EMG was normalized in two ways during these dynamic contractions: (1) to the maximal EMG values obtained during the MVIC, and (2) to the maximal M wave (Mmax) from the respective muscles.

The amplitude of the superimposed twitch (SIT) elicited by TMS is reported as a percentage of the voluntary torque measured immediately prior to TMS during the MVIC i.e. SIT $(\%)=100 \times$ SIT / (SIT + MVIC) (Gandevia et al., 1996). The SIT amplitude was also used to calculate voluntary activation for the MVIC

Experimental Gerontology, Vol 70 (October 2015): pg. 1-10. DOI. This article is @ Elsevier and permission has been granted for this version to appear in e-Publications@Marquette. Elsevier does not grant permission for this article to be further copied/distributed or hosted elsewhere without the express permission from Elsevier. 
prior to the fatiguing contraction (Todd et al., 2003). Voluntary activation was quantified by expressing the amplitude of the superimposed twitch (elicited by TMS) as a fraction of the estimated amplitude of the response evoked by the same stimulus at rest (estimated resting twitch). Because motor cortex and spinal cord excitability increase with activity (Hess et al., 1986) the amplitude of the resting twitch was estimated (eRT) rather than measured directly (Todd et al., 2003). During four brief sets of maximal and submaximal contractions (i.e. a MVIC, 60\% and $80 \%$ MVIC per set) TMS was elicited during each of these contractions. The submaximal contractions were required to estimate the resting twitch by extrapolation of the linear relation between the amplitude of the superimposed twitch and voluntary torque. One regression analysis was performed for each set of brief contractions. The $y$-intercept was taken as the estimated amplitude of the resting twitch evoked by TMS. The amplitude of the estimated resting twitch can be accurately determined from three data points in fresh or fatigued muscle when the contractions are greater than 50\% MVIC (Todd et al., 2003). For the control contractions, voluntary activation (\%) was calculated as a percentage measured by cortical stimulation [(1-SIT / eRT) $\times 100]$ (Todd et al., 2003). Data points were included for participants when the regression of the estimated twitch was $r>0.9$ (Hunter et al., 2008). Because this criteria was not met for many of the contractions during and in recovery from the dynamic fatiguing task (due to the rapidly changing fatigue state between brief contractions) only the voluntary activation during the control trials is reported.

Contractile properties of the elbow flexor muscle were also assessed including the amplitude of the estimated resting twitch and peak relaxation rates. The peak rate of relaxation was determined during each MVIC by calculating the steepest decline in torque during the EMG silence immediately following TMS (Todd et al., 2007). This was determined as the highest negative derivative of the torque for an interval of $10 \mathrm{~ms}$ between two cursors placed on either side of the decline in torque during the silent period. The steepest rate of torque decline was normalized to the total torque (MVIC plus superimposed twitch) prior to the silent period (Todd et al., 2007).

The amplitude and area of MEPs and $M$ wave were measured between two cursors placed at the start and end of the waveform for

Experimental Gerontology, Vol 70 (October 2015): pg. 1-10. DOI. This article is (C) Elsevier and permission has been granted for this version to appear in e-Publications@Marquette. Elsevier does not grant permission for this article to be further copied/distributed or hosted elsewhere without the express permission from Elsevier. 
the biceps brachii muscles. Because MEP amplitude and area showed similar changes, only MEP amplitude is reported. M waves were elicited after each MEP, so the MEP could be normalized to the ongoing $M$ wave amplitude. Voluntary torque was quantified by calculation of the mean torque over a $100 \mathrm{~ms}$ period immediately prior to TMS.

\subsection{Statistical analysis}

Data are reported as means \pm SD within the text and displayed as means \pm SEM in the figures. Univariate analyses of variance (ANOVAs) were used to compare young and old men and women for the variables: physical characteristics; physical activity levels; time to task failure; and baseline control variables including MVIC, SIT, voluntary activation, peak relaxation rate, and MEP amplitude in young and old men and women. Three-way ANOVAs with repeated measures (age and sex as a fixed factor) were used to compare the groups across time. Separate three-way repeated ANOVAs were used to compare variables for the fatiguing contraction (baseline and at task failure) and recovery (task failure and recovery at $1 \mathrm{~min}, 5 \mathrm{~min}$, $10 \mathrm{~min}$ ). The variables include MVIC torque, power during the MVCC with the $20 \%$ MVIC load, SIT, MEP and M wave amplitude, and peak relaxation rate. The strength of association is reported as the squared Pearson product-moment correlation coefficient $\left(r^{2}\right)$. To predict time to task failure, stepwise linear regression analysis was conducted using those variables that correlated with time to task failure. Statistical significance was identified as $\mathrm{P}<0.05$.

\section{Results}

\subsection{Baseline measures}

Table 1 shows the baseline data for strength, power, physical activity, voluntary activation, $M$ wave amplitude, MEP amplitude and peak rates of relaxation. Physical activity levels were similar for the young and old adults $\left(F_{1,50}=0.10, P=0.85\right)$, and were similar for men and women $\left(F_{1,50}=0.10, P=0.63\right)$. Prior to the start of each fatiguing contraction, young adults demonstrated greater MVIC torque than old adults $\left(F_{1,50}=7.94, P=0.007\right)$, and men had greater maximal torque than women $\left(F_{1,50}=81.2, P<0.001\right)$ with no age by

Experimental Gerontology, Vol 70 (October 2015): pg. 1-10. DOI. This article is (C) Elsevier and permission has been granted for this version to appear in e-Publications@Marquette. Elsevier does not grant permission for this article to be further copied/distributed or hosted elsewhere without the express permission from Elsevier. 
sex interactions $\left(F_{1,50}=0.98, P=0.33\right)$. Maximal voluntary angular velocity during the baseline MVCCs was faster for the young than old adults $\left(F_{1,50}=10.2, P=0.002\right)$, but similar for the men and women $\left(F_{1,50}=0.001, P=0.98\right)$. Average power during the baseline MVCCs therefore was greater for young than the old adults $\left(F_{1,50}=19.4\right.$, $P<0.001)$, and larger for the men than the women $\left(F_{1,50}=49.8\right.$, $\mathrm{P}<0.001$, Table 1).

Table 1. Subject characteristics and baseline values.

\begin{tabular}{|c|c|c|c|c|c|c|c|c|}
\hline \multirow[t]{2}{*}{ Variables } & \multirow[t]{2}{*}{ Unit } & \multicolumn{2}{|c|}{ Young $(n=18)$} & \multicolumn{2}{|c|}{ Old $(n=36)$} & \multicolumn{3}{|c|}{ P-value } \\
\hline & & $\begin{array}{c}\text { Men } \\
(n=9)\end{array}$ & $\begin{array}{l}\text { Women } \\
(n=9)\end{array}$ & $\begin{array}{c}\text { Men } \\
(n=16)\end{array}$ & $\begin{array}{l}\text { Women } \\
(n=20)\end{array}$ & Age & Sex & $\begin{array}{c}\text { Age } \times \text { Se } \\
x\end{array}$ \\
\hline Age & Years & $\begin{array}{l}20.8 \pm 2 . \\
8\end{array}$ & $\begin{array}{l}19.9 \pm 1 . \\
8\end{array}$ & $\begin{array}{l}73.8 \pm 6 . \\
1\end{array}$ & $\begin{array}{l}73.3 \pm 4 . \\
8\end{array}$ & $\begin{array}{l}<0.00 \\
1\end{array}$ & 0.58 & 0.86 \\
\hline Height & $\mathrm{cm}$ & $176 \pm 5.1$ & $167 \pm 6.0$ & $177 \pm 5.9$ & $162 \pm 5.2$ & 0.16 & $\begin{array}{l}<0.00 \\
1\end{array}$ & 0.12 \\
\hline Weight & $\mathrm{kg}$ & $77.6 \pm 12$ & $62.4 \pm 7$ & $86.4 \pm 12$ & $76 \pm 8$ & 0.007 & $\begin{array}{l}<0.00 \\
1\end{array}$ & 0.92 \\
\hline $\begin{array}{l}\text { Handednes } \\
\mathrm{s}\end{array}$ & & $\begin{array}{l}0.69 \pm 0 . \\
3\end{array}$ & $\begin{array}{l}0.79 \pm 0 . \\
2\end{array}$ & $\begin{array}{l}0.69 \pm 0 . \\
3\end{array}$ & $\begin{array}{l}0.73 \pm 0 . \\
3\end{array}$ & 0.79 & 0.38 & 0.74 \\
\hline $\begin{array}{l}\text { Physical } \\
\text { activity }\end{array}$ & $\begin{array}{l}\text { MET h/wee } \\
\mathrm{k}\end{array}$ & $32.9 \pm 24$ & $51.9 \pm 51$ & $41.7 \pm 49$ & $32.1 \pm 23$ & 0.85 & 0.63 & 0.12 \\
\hline $\begin{array}{l}\text { MVIC } \\
\text { torque }\end{array}$ & $\mathrm{Nm}$ & $62.5 \pm 10$ & $\begin{array}{l}36.0 \pm 8 . \\
9\end{array}$ & $52.4 \pm 11$ & $\begin{array}{l}31.1 \pm 7 . \\
1\end{array}$ & 0.007 & $\begin{array}{l}<0.00 \\
1\end{array}$ & 0.33 \\
\hline $\begin{array}{l}\text { Maximal } \\
\text { angular } \\
\text { velocity } \\
\text { during } \\
\text { MVCC }\end{array}$ & $\% / \mathrm{s}$ & $\begin{array}{l}395 \pm 10 \\
5\end{array}$ & $391 \pm 82$ & $319 \pm 66$ & $327 \pm 52$ & 0.002 & 0.98 & 0.81 \\
\hline $\begin{array}{l}\text { Power } \\
\text { during } \\
\text { MVCC }\end{array}$ & Watt & $92.1 \pm 20$ & $52.8 \pm 12$ & $63.9 \pm 20$ & $38.4 \pm 9$ & $\begin{array}{l}<0.00 \\
1\end{array}$ & $\begin{array}{l}<0.00 \\
1\end{array}$ & 0.19 \\
\hline $\begin{array}{l}\text { Voluntary } \\
\text { activation } \\
\text { (mean) }\end{array}$ & $\%$ & $\begin{array}{l}89.2 \pm 3 \\
5\end{array}$ & $\begin{array}{l}89.4 \pm 6 \\
9\end{array}$ & $\begin{array}{l}87.2 \pm 9 \\
2\end{array}$ & $\begin{array}{l}89.6 \pm 9 \\
2\end{array}$ & 0.70 & 0.59 & 0.65 \\
\hline $\begin{array}{l}\text { Voluntary } \\
\text { activation } \\
\text { (max) }\end{array}$ & $\%$ & $\begin{array}{l}93.9 \pm 4 \text {. } \\
9\end{array}$ & $\begin{array}{l}91.9 \pm 6 . \\
6\end{array}$ & $\begin{array}{l}91.1 \pm 8 . \\
7\end{array}$ & $\begin{array}{l}93.9 \pm 7 \\
9\end{array}$ & 0.86 & 0.85 & 0.26 \\
\hline $\begin{array}{l}\text { Peak rate } \\
\text { of } \\
\text { relaxation }\end{array}$ & $\mathrm{s}^{-1}$ & $\begin{array}{l}12.4 \pm 2 \\
3\end{array}$ & $8.3 \pm 2.6$ & $\begin{array}{l}10.6 \pm 1 \\
6\end{array}$ & $7.0 \pm 1.8$ & 0.009 & $\begin{array}{l}<0.00 \\
1\end{array}$ & 0.63 \\
\hline $\begin{array}{l}\text { M wave } \\
\text { amplitude } \\
\left(M_{\max }\right)\end{array}$ & $\mathrm{mV}$ & $\begin{array}{l}22.5 \pm 4 \text {. } \\
9\end{array}$ & $\begin{array}{l}22.6 \pm 1 \\
8\end{array}$ & $\begin{array}{l}19.1 \pm 5 . \\
6\end{array}$ & $\begin{array}{l}16.6 \pm 4 \\
8\end{array}$ & $\begin{array}{l}<0.00 \\
1\end{array}$ & 0.40 & 0.35 \\
\hline $\begin{array}{l}\text { MEP } \\
\text { amplitude }\end{array}$ & $\% M_{\max }$ & $57.6 \pm 22$ & $46.2 \pm 9$ & $58.1 \pm 26$ & $50.9 \pm 12$ & 0.64 & 0.09 & 0.69 \\
\hline
\end{tabular}

The baseline data from the two sessions were averaged to contribute to the young and old group data shown above. Values are means \pm SD; MVIC, maximal voluntary isometric contraction; MVCC, maximal voluntary concentric contraction; max, maximal; Nm, newton meters; cm, centimeters; kg, kilograms; METs, metabolic equivalents; hr, hour; wk, week; deg, degree; and s, seconds. 
Initial peak rates of relaxation (during baseline MVICs) were faster for the young than the old adults $\left(F_{1,50}=7.40, P=0.009\right)$, and faster for the men than the women $\left(F_{1,50}=44.2, P<0.001\right)$. Superimposed twitch (SIT) amplitude and voluntary activation elicited during the MVIC were similar in young and old adults, and between men and women prior to the fatiguing contractions (Table 1). MEP amplitude of biceps brachii normalized to $M_{\max }$ elicited during control MVICs were also similar in young and old adults $\left(F_{1,50}=0.23\right.$, $P=0.64)$, and men and women $\left(F_{1,50}=3.02, P=0.09\right.$, Table 1$)$.

\subsection{Fatigue and recovery}

\subsubsection{Time to task failure}

The time to task failure was briefer for the men than the women $\left(6.1 \pm 2.1 \mathrm{~min}\right.$ vs. $9.7 \pm 5.5 \mathrm{~min}$, respectively, sex effect: $F_{1}$, $50=7.52, \mathrm{P}=0.02)$, but did not differ between the young and old adults $\left(7.2 \pm 2.9 \mathrm{~min}\right.$ vs. $8.4 \pm 5.2 \mathrm{~min}$, respectively, $F_{1,50}=0.57$, $\mathrm{P}=0.45$ ) with no interaction ( $\operatorname{sex} \times$ age, $F_{1,50}=1.02, P=0.32$ ). See Fig. 2.

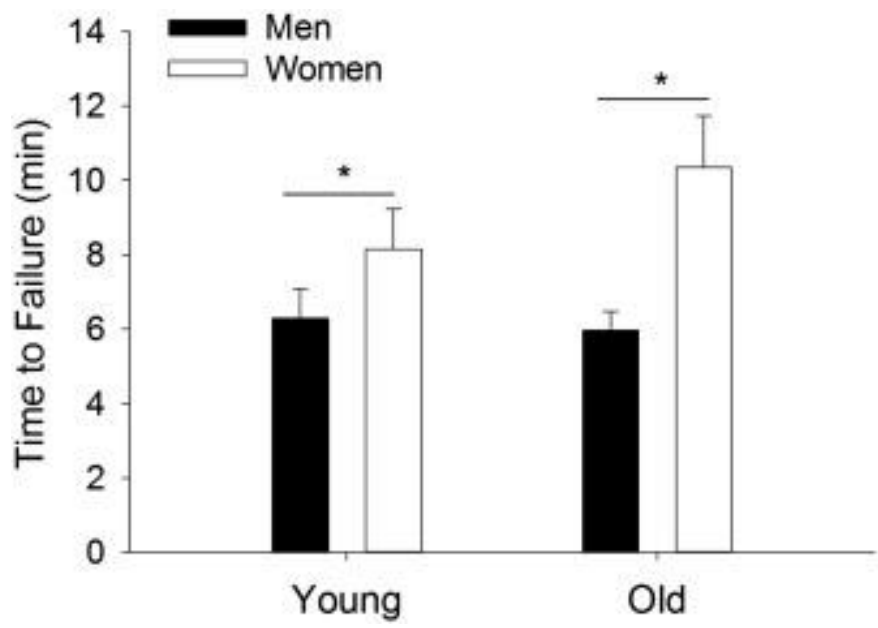

Fig. 2. Time to task failure. Time to task failure of young and older adults for the dynamic contractions. Shown are the means ( \pm SEM). There was a sex difference (sex effect, $* P=0.02)$, but no age difference and no interaction $(P>0.05)$.

\subsubsection{MVIC torque}

MVIC torque after the fatiguing contraction decreased from control values by $30.1 \pm 12.7 \%\left(F_{1,50}=28, P<0.001\right.$, Fig. $\left.3 A\right)$. The 
relative decline was similar for the young and old (fatigue $\times$ age, $F_{1}$, $50=2.68, P=0.11$ ) and for men and women (fatigue $\times$ sex, $F_{1}$, $50=0.69, P=0.79)$. During recovery, MVIC torque increased (recovery effect, $F_{3,48}=38.0, P<0.001$ ) and this was similar for the young and old (recovery $\times$ age, $F_{3,48}=0.50, P=0.69$ ) and men and women (recovery $\times$ sex, $F_{3,48}=1.58, P=0.21$ ).

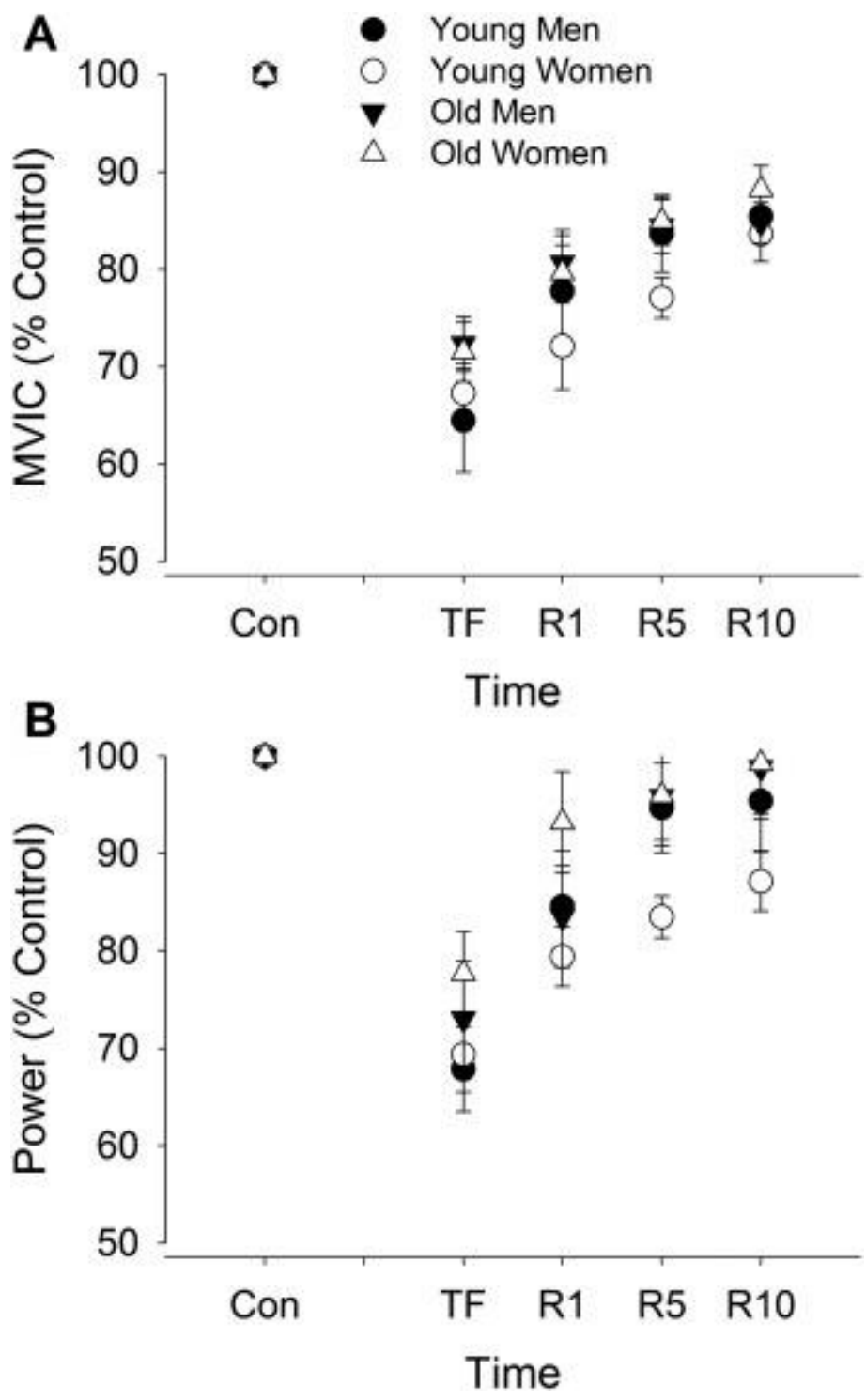

Fig. 3. Maximal voluntary isometric contraction (MVIC) and power during the maximal voluntary concentric contractions before and after a dynamic fatiguing contraction task. For the MVIC (panel A) and average power (B), values are expressed relative to control values obtained during baseline contractions (\% of control) for the young and old men and women. Shown are the means ( \pm SEM) during control trials before the fatiguing contraction (Con); at task failure (TF); and during recovery at 1 min (R1), $5 \mathrm{~min}$ (R5), and $10 \mathrm{~min}$ (R10). 


\subsubsection{Power}

Power during elbow flexion (MVCC) immediately after the fatiguing contraction decreased from control values $\left(F_{1,50}=104\right.$, $\mathrm{P}<0.001$, Fig. 3B). The relative decline was similar for the young and old (fatigue $\times$ age, $F_{1,50}=1.50, P=0.23$ ) and for men and women (fatigue $\times$ sex, $F_{1,50}=0.32, P=0.58$ ). During recovery, power increased (recovery effect, $\mathrm{F}_{3,48}=21.1, \mathrm{P}<0.001$ ) and the relative $(\%)$ increase was similar for the young and old (recovery $\times$ age, $F_{3}$, $48=0.10, P=0.96)$ and for men and women (recovery $\times$ sex, $F_{3}$, $48=1.98, \mathrm{P}=0.13)$.

\subsubsection{Peak rate of relaxation}

Peak rates of relaxation of muscle after the fatiguing contraction decreased from control values $\left(F_{1,50}=56.8, P<0.001\right.$, Fig. $\left.4 A\right)$. The relative decline in peak relaxation rate was similar for the young and old (fatigue $\times$ age, $F_{1,50}=2.7, P=0.11$ ), but greater for men compared with women (fatigue $\times$ sex, $F_{1,50}=4.17, P=0.046$ ).

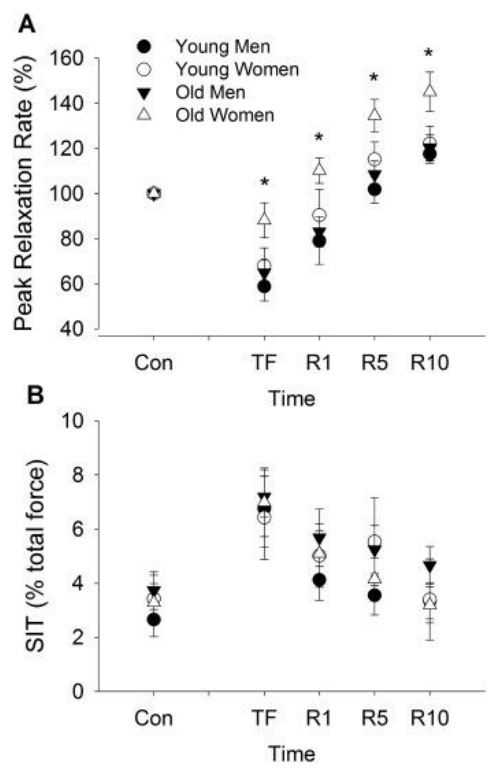

Fig. 4. Superimposed twitch (SIT) amplitude and peak relaxation rate of muscle fibers elicited from cortical stimulation during MVICs before and after a dynamic fatiguing contraction task. The peak relaxation rate $(A)$ of muscle fibers shown as a percent of control and SIT (B) expressed relative to the MVIC torque (\%) for the young and old men and women. Shown are the means ( \pm SEM) during control trials before the fatiguing contraction (Con); immediately after the fatiguing contraction (TF); and during recovery at $1 \mathrm{~min}$ (R1), $5 \mathrm{~min}$ (R5), and $10 \mathrm{~min}$ (R10). [*indicates a sex difference at $\mathrm{P}<0.05]$. 
During recovery, peak rates of relaxation increased (recovery effect, $F_{3,48}=63.8, P<0.001$ ) but women recovered more rapidly than men (sex effect, $\left.F_{1,50}=0.19, P=0.014\right)$ with no age effect $\left(F_{1}\right.$, $50=3.34, \mathrm{P}=0.074)$. The relative increase in relaxation was similar for young and old adults (recovery $\times$ age, $\mathrm{F}_{3,48}=0.02, \mathrm{P}=0.99$ ) and for men and women (recovery $\times$ sex interaction, $F_{3,48}=0.67$, $P=0.58$ ), with no other interactions (age $\times$ sex, $F_{3,48}=1.19$, $P=0.28$; recovery $\times$ age $\times$ sex: $\left.F_{3,48}=0.51, P=0.68\right)$.

\subsubsection{Superimposed Twitch (SIT)}

SIT after the fatiguing contraction increased (voluntary activation decreased) from control values $\left(F_{1,50}=33.7, P<0.001\right.$, Fig. 4B). The relative increase was similar for young and old adults (fatigue $\times$ age, $F_{1,50}=0.001, P=0.97$ ) and for men and women (fatigue $\times$ sex, $F_{1,50}=0.13, P=0.72$ ). During recovery, SIT decreased (recovery effect, $\mathrm{F}_{3,48}=12.8, \mathrm{P}<0.001$ ). The relative decrease was similar for the young and old (recovery $\times$ age, $F_{3}$, $48=0.14, P=0.94)$, and for men and women (recovery $\times$ sex, $F_{3}$, $48=0.82, \mathrm{P}=0.49$ ).

\subsubsection{M wave and Motor Evoked Potential (MEP)}

$M$ wave amplitude ( $M_{\max }$ ) elicited during the MVIC did not change during $(P=0.89)$ or in recovery $(P=0.51)$ from the dynamic fatiguing task. MEP amplitude (normalized to the $M_{\max }$ ) of biceps brachii increased immediately after the fatiguing contraction compared with control values (from 53.4 to $60.7 \%$ of $M_{\max }$, all groups combined; $\left.F_{1,50}=9.46, P=0.003\right)$. The relative increase was similar for young and old adults ( 51.9 to $56.8 \%$ vs. 54.1 to $62.3 \%$ of $M_{\max }$, young vs. old respectively; fatigue $\times$ age, $F_{1,50}=0.83, P=0.37$ ) and for men and women ( 57.9 to $68.4 \%$ vs 49.4 to $54.1 \%$ of $M_{\max }$, men vs. women respectively; fatigue $\times$ sex, $\left.\mathrm{F}_{1,50}=1.33, \mathrm{P}=0.26\right)$. During recovery, the MEP amplitude did not change (recovery effect, $F_{3,48}=2.17$, $P=0.104)$.

\subsubsection{EMG activity during the fatiguing contraction}

EMG activity was examined during 5 dynamic contraction cycles (i.e. $15 \mathrm{~s}$ of lifting and lowering were included) at the beginning and

Experimental Gerontology, Vol 70 (October 2015): pg. 1-10. DOI. This article is @ Elsevier and permission has been granted for this version to appear in e-Publications@Marquette. Elsevier does not grant permission for this article to be further copied/distributed or hosted elsewhere without the express permission from Elsevier. 
also at the end of the fatiguing contraction. EMG activity (\% MVIC) of biceps brachii increased during the dynamic task (fatigue effect, $F_{1}$, $50=64.1, \mathrm{P}<0.001$, Fig. 5). The increase of biceps brachii RMS EMG during the dynamic fatigue task was similar for young and old adults (fatigue $\times$ age, $F_{1,50}=0.26, P=0.61$ ) and for the men and women (fatigue $\times$ sex, $F_{1,50}=0.001, P=0.99$ ), with no main effect of age $\left(F_{1,50}=1.69, P=0.20\right)$ and no main effect of $\operatorname{sex}\left(F_{1,50}=0.73\right.$, $P=0.40)$. When the biceps brachii EMG was normalized to $M_{\max }$, there was no age $\left(F_{1,50}=0.34, P=0.56\right)$ nor a sex difference $\left(F_{1,50}=1.09\right.$, $P=0.30)$ in EMG activity.

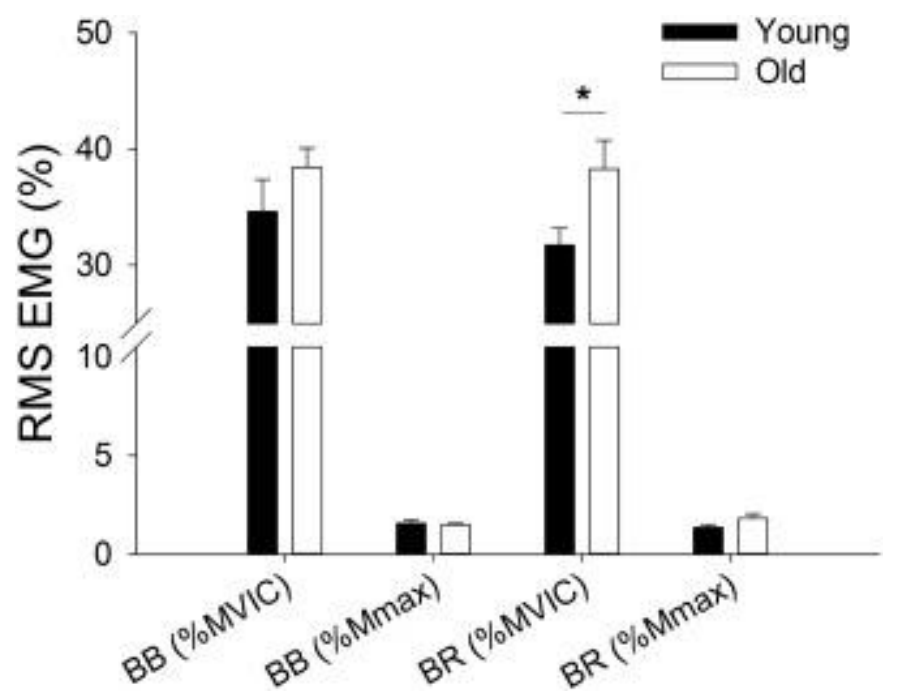

Fig. 5. EMG activity for the elbow flexor muscles averaged for that during the dynamic fatigue task performed by young and old adults. The RMS EMG ( \pm SEM) activity is shown for biceps brachii (BB) and brachioradialis (BR) values normalized to EMG during the MVIC (\% MVIC) and to the M wave (\% M $M_{\max }$ ). The brachioradialis EMG (BR\% MVIC) was greater for old than young adults (age effect, $* \mathrm{P}<0.01$ ) but similar for the age groups when normalized to the $M$ wave. There was no age effect for the biceps brachii EMG when normalized to either the MVIC or $M_{\max }$.

EMG activity (\% MVIC) of brachioradialis increased during the dynamic task (fatigue effect, $F_{1,50}=64.1, P<0.001$, Fig. 5). The increase of brachioradialis RMS EMG (\% MVIC) was similar for young and old adults (fatigue $\times$ age, $F_{1,50}=0.83, P=0.37$ ) and for the men and women (fatigue $\times$ sex, $F_{1,50}=0.06, P=0.80$ ). However brachioradialis EMG was greater for old adults (main effect of age, $F_{1}$, $50=7.53, \mathrm{P}=0.008$ ), and similar between the men and women (main effect of sex, $\left.F_{1,50}=5.04, P=0.80\right)$. To determine if this difference in EMG activity (\% MVIC) between young and old adults was due to an age difference in brachioradialis activation during the MVIC, the EMG 
was normalized to the $M$ wave for this muscle. In contrast, there was no difference in EMG activity ( $\% M_{\max }$ ) between the young and old adults (main effect of age, $F_{1,47}=2.25, P=1.40$ ), no sex difference (main effect of sex, $F_{1,47}=2.04, P=1.59$ ) and no difference in the rate of increase in EMG activity between the young and old adults (fatigue $\times$ age, $\mathrm{F}_{1,47}=3.85, \mathrm{P}=0.06$ ).

EMG activity for the triceps brachii muscle also increased during the dynamic fatigue task (26.9 $\pm 10 \%$ to $38.9 \pm 18 \%$ MVIC; fatigue effect, $\left.F_{1,50}=55.3, P<0.001\right)$, with similar RMS EMG for the young and old adults (main effect of age, $F_{1,50}=0.16, P=0.10$ ) and the men and women (main effect of sex, $F_{1,50}=0.16, P=0.69$ ) with no interactions (age $\times$ sex, $F_{1,50}=2.48, P=0.12$ ).

\subsubsection{Associations with fatigability and regression analysis}

Several baseline variables were associated with the time to failure, including the initial MVIC $\left(r=-0.290, r^{2}=0.084, P=0.034\right)$, initial power $\left(r=-0.294, r^{2}=0.086, P=0.033\right)$, initial peak rate of relaxation (during control MVIC) $\left(r=0.38, r^{2}=0.14, P=0.005\right)$, and initial SIT during baseline MVICs $\left(r=-0.27, r^{2}=0.07, P=0.048\right)$. Thus, those individuals who were stronger, had higher voluntary activation, were more powerful and had a faster peak rate of relaxation, had a briefer time to failure. Physical activity level also was associated with the time to failure, but for the young adults only $(r=0.55, P=0.018)$ and not the old adults $(r=-0.003, P=0.99)$. The time to failure was also associated with the change in peak rate of relaxation $\left(r=0.72, r^{2}=0.52, P<0.001\right)$ so that those individuals who had a greater slowing of the muscle (measured during MVICs and between baseline and that immediately after task failure) had a briefer time to task failure. The time to failure was also associated with the change in SIT during recovery $\left(r=-0.43, r^{2}=0.18, P=0.002\right)$ so that those who had a longer time to task failure also showed slower recovery of SIT.

Those variables that were associated with the time to task failure were entered into the multiple regression model and this showed that the variance in the time to task failure was primarily explained by the peak rate of relaxation and its change (slowing) at

Experimental Gerontology, Vol 70 (October 2015): pg. 1-10. DOI. This article is @ Elsevier and permission has been granted for this version to appear in e-Publications@Marquette. Elsevier does not grant permission for this article to be further copied/distributed or hosted elsewhere without the express permission from Elsevier. 
the end of the fatiguing contraction (adjusted $r^{2}=0.55 ; F_{2,50}=32.4$, $\mathrm{P}<0.001$, Table 2).

Table 2. Multiple regression analysis for time to failure $(n=54)$.

\begin{tabular}{lcccccccc}
\multicolumn{1}{r}{ Variables } & B & SE B & $\boldsymbol{\beta}$ & p-Value & \multicolumn{3}{c}{ Correlations } \\
\cline { 6 - 9 } & & & & & & Zero-order & Partial & Part \\
\% change in PRR & 0.11 & 0.02 & 0.68 & $<0.001$ & 0.73 & 0.71 & 0.66 \\
PRR at baseline & 0.34 & 0.16 & 0.21 & 0.04 & 0.36 & 0.29 & 0.20
\end{tabular}

PRR: peak rate of relaxation.

\section{Discussion}

This study investigated sex- and age-related differences in fatigability during and in recovery from a dynamic fatigue task with the elbow flexor muscles. The novel findings were that for a dynamic fatigue task: 1 ) the time to task failure was similar for young and old adults, but greater for men than for women across both age groups; 2 ) the relative decline in peak rate of muscle relaxation was greater (i.e. the muscle slowed more) for men than for women in both age groups; 3) supraspinal fatigue increased after the fatigue measured during MVIC but the increase was similar for young and old, and for men and women, and into recovery; and 4) the time to task failure was associated with the peak rate of relaxation and supraspinal fatigue but was best predicted by the initial peak rates of relaxation and the magnitude of muscle slowing (i.e. change in peak relaxation rate). Finally, the self-reported physical activity levels were similar for young and old adults, and for men and women and therefore did not drive the age- and sex-related differences in fatigability, strength and contractile function. These results suggest that mechanisms that limit excitation-contraction coupling and contractile speed are responsible for the differences in the time to task failure between old and young men and women for a slow-paced dynamic fatiguing task.

\subsection{Baseline: age and sex-related differences in maximal torque, power and contractile properties}

The elbow flexor muscles of the old men and women were weaker, slower and less powerful than the young men and women. The age difference in maximal isometric torque and maximal voluntary

Experimental Gerontology, Vol 70 (October 2015): pg. 1-10. DOI. This article is (C) Elsevier and permission has been granted for this version to appear in e-Publications@Marquette. Elsevier does not grant permission for this article to be further copied/distributed or hosted elsewhere without the express permission from Elsevier. 
angular velocity was $\sim 15 \%$, and $18 \%$, respectively. Because power is the product of torque and angular velocity, the age difference in peak power during elbow flexion ( 29\%) was greater than the age difference in maximal torque or maximal velocity alone, for both men and women, and this is consistent with the age-related deficits seen in lower and upper limb muscles (Lanza et al., 2003, Metter et al., 2004 and McNeil and Rice, 2007). These age-related differences in maximal torque at baseline suggest one or several of the following: that older adults possessed smaller muscles, a reduced muscle quality with advanced age (i.e. reduced specific tension) (Frontera et al., 2000 and McNeil et al., 2007) or greater tendon compliance than the young adults (Narici and Maganaris, 2007). Old adults did not however, exhibit reduced neural drive to the muscle compared with the young adults. At baseline, there were no age-related differences in voluntary activation (i.e. the drive to the motor cortex) or corticomotor excitability (seen as the MEP) during the MVIC (Hunter et al., 2008 and Yoon et al., 2012) indicating neural drive was not compromised in the older adults. Sarcopenia (age-related loss of muscle mass) however, involves a reduction in the number of muscle fibers and fiber size, in particular, metabolically faster fibers (type 2) (Doherty, 2003). Accordingly, older adults also had slower maximal voluntary angular velocity than the young during the concentric (shortening) phase (MVCC) and had lower peak rates of relaxation in response to cortical stimulation. Thus, older adults demonstrated slower contractile properties than young and as seen before (Valour et al., 2003 and Yoon et al., 2012). The slower muscle properties among old adults are attributed to age-related differences in fiber composition, selective reduction of type 2 and slower sarcoplasmic calcium kinetics (Hunter et al., 1999 and Klein et al., 2003). Thus, the age-related reduction in torque and contractile velocity appeared to contribute to the large power differences with age.

These age differences in maximal torque and power were similar in magnitude for the men and women, but the men were $41 \%$ stronger than the women for both age groups. The sex difference in power was due to a difference in isometric torque with a minimal sex difference in maximal angular velocity during dynamic elbow flexion with the $20 \%$ load ( 1\%). Men and women had similar levels of voluntary activation during maximal efforts at baseline (Hunter et al., 2006 and Keller et al., 2011) suggesting maximal torque and power

Experimental Gerontology, Vol 70 (October 2015): pg. 1-10. DOI. This article is @ Elsevier and permission has been granted for this version to appear in e-Publications@Marquette. Elsevier does not grant permission for this article to be further copied/distributed or hosted elsewhere without the express permission from Elsevier. 
differences between the sexes were due to differences in muscle mass. Although maximal voluntary contraction angular velocity was similar for the men and women, women had slower relaxation rates than men (Hunter et al., 2006 and Keller et al., 2011). Peak rates of relaxation represent the maximal rate of calcium uptake into the sarcoplasmic reticulum within the sarcomere and the rate of crossbridge detachment (Hunter et al., 1999). These sex differences in contractile relaxation are consistent with women possessing a slower but more oxidative, type I fiber proportional area within their muscles and slower calcium uptake into the sarcoplasmic reticulum compared with that of men (Miller et al., 1993, Hunter, 2014, Harmer et al., 2014 and Wiles et al., 1979).

\subsection{Sex difference in time to task failure maintained with age}

The time to failure of the dynamic fatiguing task was longer for women than men and this sex difference was maintained with age. The MVIC at the end of the task was reduced to similar relative magnitudes indicating that the rate of decline in maximal torque differed between the sexes. Among young adults, women are typically less fatigable than men for isometric contractions with the elbow flexor muscles for both submaximal tasks held to failure and maximal contractions (Hunter and Enoka, 2001 and Hunter et al., 2004b) but the sex difference is usually diminished among older men and women (Hunter et al., 2004a and Hunter, 2009). In contrast, for a dynamic fatiguing task at a relatively fast angular velocity ( $>\sim 340 \%$ s) with a load equivalent to $20 \%$ MVIC, there was no sex difference in fatigability of the elbow flexor muscles in young adults (Senefeld et al., 2013). Similarly, there was no sex difference during bi-lateral elbow flexion weight lifting exercise with a higher work load (80 and 90\% maximum load) at a slower rate ( 1 cycle/ $6 \mathrm{~s}$ ) than in this current study (1 cycle/3 s); although young women were less fatigable than men with loads at $50-70 \%$ of 1RM (Maughan et al., 1986). In this current study, we showed the sex difference in time to failure for a slow-paced dynamic task. Taken together, the sex difference in fatigability of arm muscles during a dynamic task appear to be specific to slow angular velocity contractions.

Experimental Gerontology, Vol 70 (October 2015): pg. 1-10. DOI. This article is (C) Elsevier and permission has been granted for this version to appear in e-Publications@Marquette. Elsevier does not grant permission for this article to be further copied/distributed or hosted elsewhere without the express permission from Elsevier. 
Both a shortening and lengthening phase of activation were involved in the dynamic fatiguing task in this study, but the participants were limited at task failure in the shortening phase rather than the lengthening phase. Each participant failed because they were not able to reach the required end point range of motion in the shortening phase when lifting the $20 \%$ MVIC load in the given time. More motor units are activated during a shortening than lengthening activation and so shortening activation requires greater contractile activity and metabolic demand (Pasquet et al., 2000). Although muscle damage can limit force production and decrease voluntary activation in the elbow flexor muscles after unaccustomed lengthening contractions (Prasartwuth et al., 2005), the light load and slow angular velocities used in the current study minimized any limitations due to muscle damage after the fatiguing task and between young and old men and women.

The sex difference in fatigability was explained primarily by those contractile mechanisms regulating the changes in the peak rates of relaxation. Both young and old women had lower (slower) peak rates of relaxation than the men at baseline, as observed in previous studies (Keller et al., 2011, Keller-Ross et al., 2014 and Hunter et al., 2006). However, the peak rates of relaxation among women changed less than the men from the start to the end of the fatiguing contraction. Although the time to task failure was weakly correlated with various variables, it was most strongly associated with the baseline peak rate of relaxation, and the change in peak rate of relaxation. Multiple regression analysis predicted that these two rates of relaxation predicted $55 \%$ of the variance in the time to task failure. The peak rates of relaxation of muscle fibers are regulated by the rate of cross bridge detachment and calcium reuptake into the sarcoplasmic reticulum (Hunter, 2014 and Hunter et al., 1999). Thus, the lesser change in the peak rates of the relaxation of the women compared with the men indicates the mechanisms regulating the speed of the calcium uptake and calcium activated excitation-contraction coupling in the muscle fiber likely led to the earlier task failure of the men. These results are consistent with studies that demonstrate that women possess slower the rates of sarcoplasmic reticulum calcium reuptake and calcium ATPase activity, greater proportional area of type 1 fibers and a more fatigue resistant muscle compared with men (Hunter, 2014 and Harmer et al., 2014). Of note the peak rates of relaxation 
recovered in all groups and to levels above baseline. This is not an unusual finding after a fatiguing contraction in young and old men and women (Keller et al., 2011 and Yoon et al., 2012) and may reflect altered contractile properties with increased muscle temperature (Todd et al., 2007). Finally, although supraspinal fatigue (amplitude of SIT) and corticospinal excitability (MEP amplitude) increased after the fatiguing contraction, there was no difference between men and women that could explain the differences in fatigability. Accordingly, the increase in EMG activity of the biceps brachii and brachioradialis muscles were similar for men and women, indicating that activation of the motoneurone pool was similar.

\subsection{No age-related differences in fatigability of arm muscles of men and women}

Despite large differences between the young and old adults in upper limb maximal torque and power, there was no age-related difference in time to failure for either sex. Further, the maximal voluntary torque, angular velocity, and power measured immediately after the fatiguing contraction decreased similarly from baseline for the young and old men and women. These results are in contrast to those found for sustained isometric contractions in which old adults are less fatigable than young for the elbow flexors (Hunter et al., 2004a, Hunter et al., 2005 and Yoon et al., 2008) and other limb muscles (Avin and Frey Law, 2011, Christie et al., 2011 and Kent-Braun, 2009). Thus, old women showed similar patterns of task specific fatigability with the elbow flexor muscles as we observed for old men (Yoon et al., 2013).

The angular velocity of the voluntary contraction is clearly a critical factor distinguishing the fatigability of old adults for a dynamic fatiguing task (Dalton et al., 2012 and Callahan and Kent-Braun, 2011). For relatively fast dynamic contractions, old adults are usually more fatigable than young adults (Dalton et al., 2010b, McNeil and Rice, 2007 and Callahan and Kent-Braun, 2011), although this has been studied only in the lower limb muscles. Most studies involving a moderate angular velocity ( 180\%/s) during a fatiguing contraction, showed similar or less fatigability in old adults than young, while those contractions executed at faster angular velocities (Dalton et al.,

Experimental Gerontology, Vol 70 (October 2015): pg. 1-10. DOI. This article is (C) Elsevier and permission has been granted for this version to appear in e-Publications@Marquette. Elsevier does not grant permission for this article to be further copied/distributed or hosted elsewhere without the express permission from Elsevier. 
2012 and Callahan and Kent-Braun, 2011) observed greater fatigability in old adults in the lower limb muscles. In this current study, the maximal angular velocity was on average relatively slow at $\sim 60 \%$ s. Studies are still needed to determine whether age-related differences in fatigability with relatively fast contraction angular velocities exist with upper limb muscles in both men and women.

This diminished age difference in the time to task failure for the dynamic task compared with isometric contractions (Dalton et al., 2010b, Kent-Braun, 2009, Yoon et al., 2013 and Baudry et al., 2007) is explained primarily by contractile mechanisms that involve calciumactivated excitation-contraction coupling. This is because the time to failure of the dynamic fatiguing contraction task was associated most strongly with the change in contractile relaxation $(r=0.72)$ so that those individuals who showed the least change in peak rate of relaxation had a longer time to failure for the dynamic fatiguing task. Thus, although the old adults had lower peak rates of relaxation than the young at baseline, indicating a greater proportional area of type I fibers (Hunter et al., 1999 and Klein et al., 2003), the change in contractile slowing was similar for the young and older adults over the fatiguing contraction.

Fatigue within the central nervous system occurred during and after the dynamic fatiguing contraction task but did not differ between young and older adults. Supraspinal fatigue was assessed as an increase in the extra torque evoked by the superimposed twitch (SIT) to the cortex (Gandevia et al., 1996 and Gandevia, 2001). Its growth indicates either that the active neurons were not all recruited voluntarily or that they were discharging at rates that were not high enough to produce full fusion of force (Gandevia, 2001). The relative increase in the SIT was similar for young and old adults. Accordingly, there was no difference in the recovery of voluntary activation after dynamic contractions, contrasting to the slower recovery of voluntary activation of supraspinal origin with aging after isometric contractions with the elbow flexor muscles (Yoon et al., 2013, Yoon et al., 2012 and Hunter et al., 2008). Furthermore, the MEP (normalized to the $M$ wave) increased similarly for the young and older adults after the fatiguing contraction. Because $M$ wave amplitude was similar for the young and old adults before and immediately after the dynamic task, the increase in the MEP probably reflects an increase in cortical

Experimental Gerontology, Vol 70 (October 2015): pg. 1-10. DOI. This article is (C) Elsevier and permission has been granted for this version to appear in e-Publications@Marquette. Elsevier does not grant permission for this article to be further copied/distributed or hosted elsewhere without the express permission from Elsevier. 
drive to compensate for less responsive motoneurones (McNeil et al., 2011 and Gandevia, 2001).

The EMG activity of elbow flexor muscles increased during dynamic contractions for both age groups, probably due to an increase in the motor unit recruitment and changes in the discharge rates to compensate for a reduced force-generating capacity of the active muscle fibers (Garland et al., 1994 and Riley et al., 2008). When normalized to the maximal muscle compound action potential ( $M$ wave), the EMG activity of both the biceps brachii and brachioradialis muscles was similar for young and old adults during the fatiguing contraction. In contrast, when the EMG activity was normalized to the EMG during the MVIC, the old men and women had higher levels of EMG activity of brachioradialis muscle compared with the young men and women at the start and end of the dynamic fatigue task. These results probably reflect inadequate activation of the old adult's brachioradialis muscle during the MVIC rather than age differences in neural strategy during the dynamic fatiguing task.

In summary, there was a sex difference in fatigability for a dynamic fatiguing task with a load at $20 \%$ of maximal torque with the elbow flexor muscles and this sex difference was maintained with aging. The change in peak rates of relaxation was less for women than men during the dynamic fatiguing task indicating that rate limiting contractile mechanisms that may include calcium-activated excitationcontraction coupling were likely responsible for the sex differences in fatigability. Finally, the age-related advantage in fatigability typically observed during the isometric fatiguing contractions with the elbow flexor muscles, was diminished during a slow angular velocity dynamic fatiguing task in both men and women, primarily due to contractile mechanisms.

\section{Acknowledgments}

This research was supported by a National Institute of Aging grant [R15AG30730] to SKH and the National Research Foundation of Korea Grant funded by the Korean government [NRF-2009-352-G00020] to TY.

Experimental Gerontology, Vol 70 (October 2015): pg. 1-10. DOI. This article is (C) Elsevier and permission has been granted for this version to appear in e-Publications@Marquette. Elsevier does not grant permission for this article to be further copied/distributed or hosted elsewhere without the express permission from Elsevier 
NOT THE PUBLISHED VERSION; this is the author's final, peer-reviewed manuscript. The published version may be accessed by following the link in the citation at the bottom of the page.

\section{References}

Avin and Frey Law, 2011. K.G. Avin, L.A. Frey Law. Age-related differences in muscle fatigue vary by contraction type: a meta-analysis. Phys. Ther., 91 (8) (2011), pp. 1153-1165

Baudry et al., 2007. S. Baudry, M. Klass, B. Pasquet, J. Duchateau. Agerelated fatigability of the ankle dorsiflexor muscles during concentric and eccentric contractions. Eur. J. Appl. Physiol., 100 (5) (2007), pp. 515-525

Callahan and Kent-Braun, 2011. D.M. Callahan, J.A. Kent-Braun. Effect of old age on human skeletal muscle force-velocity and fatigue properties. $J$. Appl. Physiol., 111 (5) (2011), pp. 1345-1352

Callahan et al., 2009. D.M. Callahan, S.A. Foulis, J.A. Kent-Braun. Age-related fatigue resistance in the knee extensor muscles is specific to contraction mode. Muscle Nerve, 39 (5) (2009), pp. 692-702

Christie et al., 2011. A. Christie, E.M. Snook, J.A. Kent-Braun. Systematic review and meta-analysis of skeletal muscle fatigue in old age. Med. Sci. Sports Exerc., 43 (4) (2011), pp. 568-577

Clark et al., 2003. B.C. Clark, T.M. Manini, D.J. The, N.A. Doldo, L.L. PloutzSnyder. Gender differences in skeletal muscle fatigability are related to contraction type and EMG spectral compression. J. Appl. Physiol., 94 (6) (2003), pp. 2263-2272

Dalton et al., 2010a. B.H. Dalton, B. Harwood, A.W. Davidson, C.L. Rice. Recovery of motoneuron output is delayed in old men following highintensity fatigue. J. Neurophysiol., 103 (2) (2010), pp. 977-985

Dalton et al., 2010b. B.H. Dalton, G.A. Power, A.A. Vandervoort, C.L. Rice. Power loss is greater in old men than young men during fast plantar flexion contractions. J. Appl. Physiol., 109 (5) (2010), pp. 1441-1447

Dalton et al., 2012. B.H. Dalton, G.A. Power, A.A. Vandervoort, C.L. Rice. The age-related slowing of voluntary shortening velocity exacerbates power loss during repeated fast knee extensions. Exp. Gerontol., 47 (1) (2012), pp. 85-92

Doherty, 2003. T.J. Doherty. Invited review: aging and sarcopenia. J. Appl. Physiol., 95 (4) (2003), pp. 1717-1727

Enoka, 2012. R.M. Enoka. Muscle fatigue - from motor units to clinical symptoms. J. Biomech., 45 (3) (2012), pp. 427-433

Frontera et al., 2000. W.R. Frontera, D. Suh, L.S. Krivickas, V.A. Hughes, R. Goldstein, R. Roubenoff. Skeletal muscle fiber quality in older men and women. Am. J. Physiol. Cell Physiol., 279 (3) (2000), pp. C611-C618

Gandevia, 2001. S.C. Gandevia. Spinal and supraspinal factors in human muscle fatigue. Physiol. Rev., 81 (4) (2001), pp. 1725-1789

Gandevia et al., 1996. S.C. Gandevia, G.M. Allen, J.E. Butler, J.L. Taylor. Supraspinal factors in human muscle fatigue: evidence for suboptimal

Experimental Gerontology, Vol 70 (October 2015): pg. 1-10. DOI. This article is @ Elsevier and permission has been granted for this version to appear in e-Publications@Marquette. Elsevier does not grant permission for this article to be further copied/distributed or hosted elsewhere without the express permission from Elsevier. 
NOT THE PUBLISHED VERSION; this is the author's final, peer-reviewed manuscript. The published version may be accessed by following the link in the citation at the bottom of the page.

output from the motor cortex. J. Physiol., 490 (2) (1996), pp. 529536

Garland et al., 1994. S. Garland, R. Enoka, L. Serrano, G. Robinson. Behavior of motor units in human biceps brachii during a submaximal fatiguing contraction. J. Appl. Physiol., 76 (6) (1994), pp. 2411-2419

Harmer et al., 2014. A.R. Harmer, P.A. Ruell, S.K. Hunter, M.J. McKenna, J.M. Thom, D.J. Chisholm, J.R. Flack. Effects of type 1 diabetes, sprint training and sex on skeletal muscle sarcoplasmic reticulum $\mathrm{Ca}^{2}+$ uptake and $\mathrm{Ca}^{2+}$ - ATPase activity. J. Physiol., 592 (2014), pp. 523535

Hermens et al., 2000. H. Hermens, L. Freriks, R. Merletti, G. Hägg, D. Stegeman, J. Blok, G. Rau, C. Disselhorst-Klug. SENIAM 8: European Recommendations for Surface ElectroMyoGraphy. Roessingh Research and Development B.V. (2000)

Hess et al., 1986. C.W. Hess, K.R. Mills, N.M. Murray. Magnetic stimulation of the human brain: facilitation of motor responses by voluntary contraction of ipsilateral and contralateral muscles with additional observations on an amputee. Neurosci. Lett., 71 (2) (1986), pp. 235240

Hunter, 2009. S.K. Hunter. Sex differences and mechanisms of task-specific muscle fatigue. Exerc. Sport Sci. Rev., 37 (3) (2009), pp. 113-122

Hunter, 2014. S.K. Hunter. Sex differences in human fatigability: mechanisms and insight to physiological responses. Acta Physiol., 210 (4) (2014), pp. 768-789

Hunter and Enoka, 2001. S.K. Hunter, R.M. Enoka. Sex differences in the fatigability of arm muscles depends on absolute force during isometric contractions. J. Appl. Physiol., 91 (6) (2001), pp. 2686-2694

Hunter et al., 1999. S.K. Hunter, M.W. Thompson, P.A. Ruell, A.R. Harmer, J.M. Thom, T.H. Gwinn, R.D. Adams. Human skeletal sarcoplasmic reticulum $\mathrm{Ca}^{2}+$ uptake and muscle function with aging and strength training. J. Appl. Physiol., 86 (6) (1999), pp. 1858-1865

Hunter et al., 2004a. S.K. Hunter, A. Critchlow, R.M. Enoka. Influence of aging on sex differences in muscle fatigability. J. Appl. Physiol., 97 (2004), pp. 1723-1732

Hunter et al., 2004b. S.K. Hunter, A. Critchlow, I.S. Shin, R.M. Enoka. Men are more fatigable than strength-matched women when performing intermittent submaximal contractions. J. Appl. Physiol., 96 (2004), pp. 2125-2132

Hunter et al., 2005. S.K. Hunter, A. Critchlow, R.M. Enoka. Muscle endurance is greater for old men compared with strength-matched young men. $J$. Appl. Physiol., 99 (2005), pp. 890-897

Hunter et al., 2006. S.K. Hunter, J.E. Butler, G. Todd, S.C. Gandevia, J.L. Taylor. Supraspinal fatigue does not explain the sex difference in

Experimental Gerontology, Vol 70 (October 2015): pg. 1-10. DOI. This article is (C) Elsevier and permission has been granted for this version to appear in e-Publications@Marquette. Elsevier does not grant permission for this article to be further copied/distributed or hosted elsewhere without the express permission from Elsevier. 
NOT THE PUBLISHED VERSION; this is the author's final, peer-reviewed manuscript. The published version may be accessed by following the link in the citation at the bottom of the page.

muscle fatigue of maximal contractions. J. Appl. Physiol., 101 (4) (2006), pp. 1036-1044

Hunter et al., 2008. S.K. Hunter, G. Todd, J.E. Butler, S.C. Gandevia, J.L. Taylor. Recovery from supraspinal fatigue is slowed in old adults after fatiguing maximal isometric contractions. J. Appl. Physiol., 105 (2008), pp. 1199-1209

Keller et al., 2011. M.L. Keller, J. Pruse, T. Yoon, B. Schlinder-Delap, A. Harkins, S.K. Hunter. Supraspinal fatigue is similar in men and women for a low-force fatiguing contraction. Med. Sci. Sports Exerc., 43 (10) (2011), pp. 1873-1883

Keller-Ross et al., 2014. M.L. Keller-Ross, H.M. Pereira, J. Pruse, T. Yoon, B. Schlinder-Delap, K.A. Nielson, S.K. Hunter. Stressor-induced increase in muscle fatigability of young men and women is predicted by strength but not voluntary activation. J. Appl. Physiol., 116 (7) (2014), pp. 767-778

Kent-Braun, 2009. J.A. Kent-Braun. Skeletal muscle fatigue in old age: whose advantage? Exerc. Sport Sci. Rev., 37 (1) (2009), pp. 3-9

Kent-Braun et al., 2012. J.A. Kent-Braun, R.H. Fitts, A. Christie. Skeletal muscle fatigue. Compr. Physiol., 2 (2) (2012), pp. 997-1044

Klein et al., 2003. C.S. Klein, G.D. Marsh, R.J. Petrella, C.L. Rice. Muscle fiber number in the biceps brachii muscle of young and old men. Muscle Nerve, 28 (1) (2003), pp. 62-68

Kluger et al., 2013. B.M. Kluger, L.B. Krupp, R.M. Enoka. Fatigue and fatigability in neurologic illnesses: proposal for a unified taxonomy. Neurology, 80 (4) (2013), pp. 409-416

Kriska and Bennett, 1992. A.M. Kriska, P.H. Bennett. An epidemiological perspective of the relationship between physical activity and NIDDM: from activity assessment to intervention. Diabetes Metab. Rev., 8 (4) (1992), pp. 355-372

Lanza et al., 2003. I.R. Lanza, T.F. Towse, G.E. Caldwell, D.M. Wigmore, J.A. Kent-Braun. Effects of age on human muscle torque, velocity, and power in two muscle groups. J. Appl. Physiol., 95 (6) (2003), pp. 2361-2369

Lindstrom et al., 1997. B. Lindstrom, J. Lexell, B. Gerdle, D. Downham. Skeletal muscle fatigue and endurance in young and old men and women. J. Gerontol. A Biol. Sci. Med. Sci., 52 (1) (1997), pp. B59-B66

Maughan et al., 1986. R. Maughan, M. Harmon, J. Leiper, D. Sale, A. Delman. Endurance capacity of untrained males and females in isometric and dynamic muscular contractions. Eur. J. Appl. Physiol., 55 (1986), pp. 395-400

McNeil and Rice, 2007. C.J. McNeil, C.L. Rice. Fatigability is increased with age during velocity-dependent contractions of the dorsiflexors. $J$. Gerontol. A Biol. Sci. Med. Sci., 62A (6) (2007), pp. 624-629

Experimental Gerontology, Vol 70 (October 2015): pg. 1-10. DOI. This article is (c) Elsevier and permission has been granted for this version to appear in e-Publications@Marquette. Elsevier does not grant permission for this article to be further copied/distributed or hosted elsewhere without the express permission from Elsevier 
McNeil et al., 2007. C.J. McNeil, A.A. Vandervoort, C.L. Rice. Peripheral impairments cause a progressive age-related loss of strength and velocity-dependent power in the dorsiflexors. J. Appl. Physiol., 102 (5) (2007), pp. 1962-1968

McNeil et al., 2011. C.J. McNeil, S. Giesebrecht, S.C. Gandevia, J.L. Taylor. Behaviour of the motoneurone pool in a fatiguing submaximal contraction. J. Physiol., 589 (2011), pp. 3533-3544

Metter et al., 2004. E.J. Metter, L.A. Talbot, M. Schrager, R.A. Conwit. Armcranking muscle power and arm isometric muscle strength are independent predictors of all-cause mortality in men. J. Appl. Physiol., 96 (2) (2004), pp. 814-821

Miller et al., 1993. A.E. Miller, J.D. MacDougall, M.A. Tarnopolsky, D.G. Sale. Gender differences in strength and muscle fiber characteristics. Eur. J. Appl. Physiol., 66 (3) (1993), pp. 254-262

Narici and Maganaris, 2007. M.V. Narici, C.N. Maganaris. Plasticity of the muscle-tendon complex with disuse and aging. Exerc. Sport Sci. Rev., 35 (3) (2007), pp. 126-134

Newham et al., 1995. D.J. Newham, D.A. Jones, D.L. Turner, D. McIntyre. The metabolic costs of different types of contractile activity of the human adductor pollicis muscle. J. Physiol., 488 (1995), pp. 815-819

Oldfield, 1971. R.C. Oldfield. The assessment and analysis of handedness: the Edinburgh Inventory. Neuropsychologia, 9 (1971), pp. 97-113

Pasquet et al., 2000. B. Pasquet, A. Carpentier, J. Duchateau, K. Hainaut. Muscle fatigue during concentric and eccentric contractions. Muscle Nerve, 23 (11) (2000), pp. 1727-1735

Petrella et al., 2005. J.K. Petrella, J.S. Kim, S.C. Tuggle, S.R. Hall, M.M. Bamman. Age differences in knee extension power, contractile velocity, and fatigability. J. Appl. Physiol., 98 (1) (2005), pp. 211-220

Pincivero et al., 2003. D.M. Pincivero, C.M. Gandaio, Y. Ito. Gender-specific knee extensor torque, flexor torque, and muscle fatigue responses during maximal effort contractions. Eur. J. Appl. Physiol., 89 (2) (2003), pp. 134-141

Pincivero et al., 2004. D.M. Pincivero, A.J. Coelho, R.M. Campy. Gender differences in perceived exertion during fatiguing knee extensions. Med. Sci. Sports Exerc., 36 (1) (2004), pp. 109-117

Prasartwuth et al., 2005. O. Prasartwuth, J.L. Taylor, S.C. Gandevia. Maximal force, voluntary activation and muscle soreness after eccentric damage to human elbow flexor muscles. J. Physiol., 567 (Pt 1) (2005), pp. $337-348$

Riley et al., 2008. Z.A. Riley, A.H. Maerz, J.C. Litsey, R.M. Enoka. Motor unit recruitment in human biceps brachii during sustained voluntary contractions. J. Physiol., 586 (8) (2008), pp. 2183-2193

Experimental Gerontology, Vol 70 (October 2015): pg. 1-10. DOI. This article is (C) Elsevier and permission has been granted for this version to appear in e-Publications@Marquette. Elsevier does not grant permission for this article to be further copied/distributed or hosted elsewhere without the express permission from Elsevier. 
NOT THE PUBLISHED VERSION; this is the author's final, peer-reviewed manuscript. The published version may be accessed by following the link in the citation at the bottom of the page.

Senefeld et al., 2013. J. Senefeld, T. Yoon, M.H. Bement, S.K. Hunter. Fatigue and recovery from dynamic contractions in men and women differ for arm and leg muscles. Muscle Nerve, 48 (3) (2013), pp. 436-439

Todd et al., 2003. G. Todd, J.L. Taylor, S.C. Gandevia. Measurement of voluntary activation of fresh and fatigued human muscles using transcranial magnetic stimulation. J. Physiol., 551 (2003), pp. 661671

Todd et al., 2004. G. Todd, J.L. Taylor, S.C. Gandevia. Reproducible measurement of voluntary activation of human elbow flexors with motor cortical stimulation. J. Appl. Physiol., 97 (1) (2004), pp. 236242

Todd et al., 2007. G. Todd, J.L. Taylor, J.E. Butler, P.G. Martin, R.B. Gorman, $\mathrm{S}$. Gandevia. Use of motor cortex stimulation to measure simultaneously the changes in dynamic muscle properties and voluntary activation in human muscles. J. Appl. Physiol., 102 (2007), pp. $1756-1766$

Valour et al., 2003. D. Valour, J. Ochala, Y. Ballay, M. Pousson. The influence of ageing on the force-velocity-power characteristics of human elbow flexor muscles. Exp. Gerontol., 38 (4) (2003), pp. 387-395

Wiles et al., 1979. C.M. Wiles, A. Young, D.A. Jones, R.H. Edwards. Relaxation rate of constituent muscle-fibre types in human quadriceps. Clin. Sci., 56 (1) (1979), pp. 47-52

Yoon et al., 2008. T. Yoon, B. Schlinder Delap, E.E. Griffith, S.K. Hunter. Agerelated muscle fatigue after a low-force fatiguing contraction is explained by central fatigue. Muscle Nerve, 37 (4) (2008), pp. 457466

Yoon et al., 2012. T. Yoon, B. Schlinder-Delap, M.L. Keller, S.K. Hunter. Supraspinal fatigue impedes recovery from a low-intensity sustained contraction in old adults. J. Appl. Physiol., 112 (5) (2012), pp. 849858

Yoon et al., 2013. T. Yoon, B. Schlinder-Delap, S.K. Hunter. Fatigability and recovery of arm muscles with advanced age for dynamic and isometric contractions. Exp. Gerontol., 48 (2) (2013), pp. 259-268

Corresponding author at: Department of Physical Therapy Marquette University P.O. Box 1881 Milwaukee, 53201 WI, United States.

Experimental Gerontology, Vol 70 (October 2015): pg. 1-10. DOI. This article is (C) Elsevier and permission has been granted for this version to appear in e-Publications@Marquette. Elsevier does not grant permission for this article to be further copied/distributed or hosted elsewhere without the express permission from Elsevier. 